\title{
Determination of Fatty Acid Methyl Esters Derived from Algae Scenedesmus dimorphus Biomass by GC-MS with One-step Esterification of Free Fatty Acids and Transesterification of Glycerolipids
}

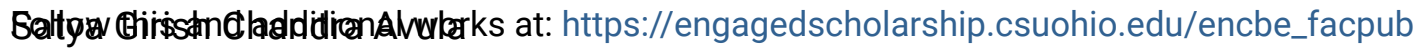
ryeland State University Part of the Chemical Engineering Commons

Hoanneds. Bredesicto this work benefit you? Let us know!

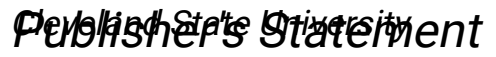

Ihis Xis the accepted version of the following article: Avula, S. G. C.; Belovich, J. M.; Xu, Y.,

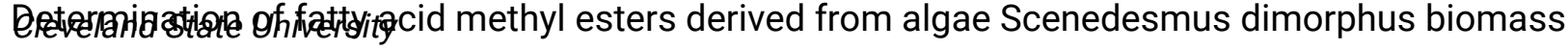
by GC-MS with one-step esterification of free fatty acids and transesterification of glycerolipids. Journal of Separation Science 2017, 40, (10), 2214-2227.], which has been published in final form at http://onlinelibrary.wiley.com/doi/10.1002/ jssc. 201601336 abstract;jsessionid=9C0A6FB5912FD46463D86076A610B8E8.f02t02

\section{Original Citation}

Avula, S. G. C.; Belovich, J. M.; Xu, Y., Determination of fatty acid methyl esters derived from algae Scenedesmus dimorphus biomass by GC-MS with one-step esterification of free fatty acids and transesterification of glycerolipids. Journal of Separation Science 2017, 40, (10), 2214-2227.

\section{Repository Citation}

Avula, Satya Girish Chandra; Belovich, Joanne M.; and Xu, Yan, "Determination of Fatty Acid Methyl Esters Derived from Algae Scenedesmus dimorphus Biomass by GC-MS with One-step Esterification of Free Fatty Acids and Transesterification of Glycerolipids" (2017). Chemical \& Biomedical Engineering Faculty Publications. 132. https://engagedscholarship.csuohio.edu/encbe_facpub/132

This Article is brought to you for free and open access by the Chemical \& Biomedical Engineering Department at EngagedScholarship@CSU. It has been accepted for inclusion in Chemical \& Biomedical Engineering Faculty Publications by an authorized administrator of EngagedScholarship@CSU. For more information, please contact library.es@csuohio.edu. 


\title{
Determination of fatty acid methyl esters derived from algae Scenedesmus dimorphus biomass by GC-MS with one-step esterification of free fatty acids and transesterification of glycerolipids
}

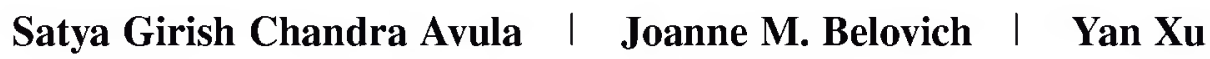

\begin{abstract}
Algae can synthesize, accumulate and store large amounts of lipids in its cells, which holds immense potential as a renewable source of biodiesel. In this work, we have developed and validated a GC-MS method for quantitation of fatty acids and glycerolipids in forms of fatty acid methyl esters derived from algae biomass. Algae Scenedesmus dimorphus dry mass was pulverized by mortar and pestle, then extracted by the modified Folch method and fractionated into free fatty acids and glycerolipids on aminopropyl solid-phase extraction cartridges. Fatty acid methyl esters were produced by an optimized one-step esterification of fatty acids and transesterification of glycerolipids with boron trichloride/methanol. The matrix effect, recoveries and stability of fatty acids and glycerolipids in algal matrix were first evaluated by spiking stable isotopes of pentadecanoic-2,2- $\mathrm{d}_{2}$ acid and glyceryl tri(hexadecanoate-2,2- $\mathrm{d}_{2}$ ) as surrogate analytes and tridecanoic-2,2- $\mathrm{d}_{2}$ acid as internal standard into algal matrix prior to sample extraction. Later, the method was validated in terms of lower limits of quantitation, linear calibration ranges, intra- and inter-assay precision and accuracy using tridecanoic-2,2- $\mathrm{d}_{2}$ acid as internal standard. The method developed has been applied to the quantitation of fatty acid methyl esters from free fatty acid and glycerolipid fractions of algae Scenedesmus dimorphus.
\end{abstract}

\section{K E Y W O R D S}

algae, esterification, fatty acid methyl esters, gas chromatography-mass spectrometry, Scenedesmus dimorphus

\section{1 | INTRODUCTION}

The interest in biofuels as an alternative renewable source of energy has increased over the recent years due to the concerns of consumption of fossil fuels and maintenance of

\footnotetext{
Abbreviations: $\mathrm{BCl}_{3}-\mathrm{MeOH}$, boron trichloride/methanol; $\mathrm{CV}$, coefficient of variation; EIC, extracted ion chromatogram; FAME, fatty acid methyl ester; IS, internal standard; LLOQ, lower limit of quantitation; MF, matrix factor; $\mathrm{RE}$, relative error
}

Conflict of interest: The authors declare that there is no conflict of interest. ecosystems. Biodiesel is often produced from agricultural biomasses such as vegetables, animals or algae, and comprised of mono-alkyl esters of long-chain fatty acids (e.g., $\mathrm{C}_{12}$ to $\mathrm{C}_{24}$ ) with over $90 \%$ of them being between $\mathrm{C}_{16}$ and $\mathrm{C}_{18}$ [1]. Among the biomasses, algae stands out because its oil yield is nearly an order of magnitude higher than the others [2], and unicellular aquatic green algae Chlorophyceae is the most desirable class since it can double its biomass in less than $24 \mathrm{~h}$. Scenedesmus dimorphus, an algal species under Chlorophyceae class, is one of the best for oil production [3].

Algae is a simple autotrophic organism that is made up of proteins, carbohydrates, lipids (biodiesel precursors) and 
other bioactive compounds. While the percent content of lipids may vary from species to species, Scenedesmus dimorphus can accumulate lipids up to $40 \%$ of their dry masses [4, 5]. It is these lipids that can be converted to fatty acid methyl esters (FAMEs).

Increasing lipid content in algal biomass would be one of the effective ways to overcome the high cost of biodiesel production. Hence, a substantial effort has been made by the researchers over the past few years. It was found that factors such as nitrogen [6], light intensity [7], temperature [8], nutrients $[9,10]$, carbon dioxide, growth stages, organic carbon content [11] and salt stress [12] were found to affect the accumulation and profile of lipids in algae.

It is worth noting that among all classes of lipids in algal cells (e.g., glycerolipids, glycerophospholipids, cholesterol, etc.), only glycerolipids (monoglycerides, diglycerides and triglycerides) can be converted to FAMEs for use in the traditional unmodified diesel engines, due to lack of phosphorus and sulfur groups in their structures [13]. While glycerophospholipids hinders the transesterification process, sulfur content is regulated in vehicle emissions [14]. It is known that the chemical nature of fatty-acid chains of glycerolipid determines the quality of biodiesel (FAMEs). Generally, cetane number, viscosity, density, flash point, heat of combustion and lubricity are determined by the structure and length of fatty acids [15]. For example, the polyunsaturated fatty acids affect cold flow properties of biodiesel, whereas the saturated fatty acids provide oxidative stability and ignition properties [14]. Hence, it is important to know the chemical structures, and the quantity of fatty acids and glycerolipids in algae biomass, particularly, the saturated and unsaturated fatty acids with carbon numbers of 16 and 18 [i.e., palmitic acid (C16:0), palmitoleic acid (C16:1), stearic acid (C18:0), oleic acid (C18:1), linoleic acid (C18:2) and linolenic acid (C18:3)] which are viable indicators for the assessment of biodiesel quality [16].

Over the past few years, much effort has been devoted to the quantitative determination of glycerolipids and fatty acids in algae by various analytical techniques $[17,18]$. Chen and his colleagues [19] developed and used a two-step microwave assisted Nile red staining method for the quantification of neutral lipids in green algae. In another study, Soh and Zimmerman used LC-MS to quantify the concentration of fatty acid methyl esters from lipids, phospholipids and pigments extracted under various supercritical temperatures and pressures [20]. McNichol and his associates [21] used 18 different algal strains to investigate the effectiveness of using automated Soxhlet extraction. They carried out the identification and quantification using GC with flame ionization detection (FID) and HPLC with charged aerosol detection (CAD). In another study, Sakthivel, Elumalai and Santhiya [22] studied the changes in lipid production of the algal strains, Scenedesmus dimorphus and Chlorococcum infusionum under the influence of light and dark conditions by GC-MS. Recently, Shah and his group [23] analyzed and characterized the algal oil from Scenedesmus dimorphus by thin layer paper and GC techniques for the high production of biodiesel. Although most of the published articles were on the measurement of total content of fatty acids, Paik and coworkers [24] did successfully quantify triacylglycerols and free fatty acids by GC-MS upon their separation using SPE. The triacylglycerols were saponified, acidified, extracted and esterified with tert-butyldimethylsilyl, while the FFA was directly acidified, extracted and esterified for GC analysis. Although several methods were used over the previous years for the analysis of lipids, these methods were not cost effective, time-consuming and are not validated.

Hence, in this work, we developed and optimized a simple and rapid GC-MS method for quantitation of FAMEs by one-step esterification of free fatty acids and transesterification of glycerolipids. The method developed was validated in terms of matrix effect, recovery, lower limits of quantitation (LLOQ), linear calibration ranges, intra- and inter-assay precision and accuracy, as well as stability. It was applied to the composition and content analyses of fatty acids and glycerolipids in algae Scenedesmus dimorphus dry mass.

\section{2 | MATERIALS AND METHODS}

\section{1 | Chemicals}

HPLC-grade acetonitrile, chloroform and hexane were purchased from Pharmco-AAPER (Louisville, KY, USA). Boron trichloride/methanol $\left(\mathrm{BCl}_{3}-\mathrm{MeOH}, 12 \% \mathrm{w} / \mathrm{w}\right)$ and 2,2-dimethoxypropane were from Sigma-Aldrich (St. Louis, MO, USA). Fatty acid standards [i.e., palmitic acid (C16:0), palmitoleic acid (C16:1), stearic acid (C18:0), oleic acid (C18:1), linoleic acid (C18:2), linolenic acid (C18:3)] were from MP Biomedicals (Solon, OH, USA). Deuterated fatty acid and glycerolipid standards [i.e., pentadecanoic-2,2- $\mathrm{d}_{2}$ acid, tridecanoic-2,2- $\mathrm{d}_{2}$ acid, and glyceryl tri(hexadecanoate-2,2- $\mathrm{d}_{2}$ )] were purchased from CDN Isotopes (Pointe-Claire, Quebec, Canada). FAME mixed standards (AOCS Mix 6, $50.0 \mathrm{mg}$ FAMEs/50.0 $\mu \mathrm{L}$ hexane) (containing methyl myristate (C14:0), $2.01 \%(\mathrm{w} / \mathrm{v})$; methyl palmitate (C16:0), 29.81\% (w/v); methyl palmitoleate (C16:1, cis), 3.17\% (w/v); methyl stearate $(\mathrm{C} 18: 0), 13.91 \%(\mathrm{w} / \mathrm{v})$; methyl oleate $(\mathrm{C} 18: 1$, cis-9), 40.95\% (w/v); methyl linoleate (C18:2, cis, cis), $6.98 \%(\mathrm{w} / \mathrm{v})$; and methyl linolenate (C18:3, all cis), $3.17 \%$ (w/v)) (Catalog \#: 625030) were obtained from Grace Davison Discovery Sciences (Waltham, MA, USA). All other chemicals were ordered from Sigma-Aldrich (St. Louis, MO, USA). Type 1 deionized water (with a resistance reading of $18.2 \mathrm{M} \Omega \cdot \mathrm{cm}$ ) was made freshly by a Barnstead NANOpure® 
water purification system (Thermo Scientific, Waltham, MA, USA).

\subsection{Algal culture and sample preparation}

Algae Scenedesmus dimorphus (strain \#: UTEX 1237) stock (in agar) was obtained from the UTEX The Culture Collection of Algae (Austin, TX, USA). Algal cultures used in the growth experiments were prepared by inoculating algal cells in agar medium into a $1 \mathrm{~L}$ bottle containing $750 \mathrm{~mL}$ of $3 \mathrm{~N}$ BB medium [25] and kept in a sterile hood. The bottles were sparged with $5 \% \mathrm{CO}_{2}$ in air at a flow rate of $0.1 \mathrm{~L} / \mathrm{min}$, and continuously agitated on a stir plate at room temperature. Illumination was provided by a Bulbrite F14T5/830 14-watt linear fluorescent T5 bulb (14 W, 24") (Bulbrite, Moonachie, NJ, USA) on a $12 \mathrm{~h}$ on/ $12 \mathrm{~h}$ off cycle with a measured intensity of 150-200 ft candles at the liquid surface.

The algal cells were harvested after 12 days of growth using a common procedure followed by the algal research community $[8,20,25]$. In this procedure, $50 \mathrm{~mL}$ of algal culture was centrifuged by a Sorvall ST 40R centrifuge of Thermo Scientific (Waltham, MA, USA) at $872 \times g$ for $20 \mathrm{~min}$. The supernatant was decanted, and the cell pellets were re-suspended in $50 \mathrm{~mL}$ of deionized water and centrifuged for another $20 \mathrm{~min}$ at $872 \times g$ to remove the remaining salts and other unwanted soluble species. The supernatant was poured off to the waste and the remaining cell pellets were dried for 2 days at $45^{\circ} \mathrm{C}$ in a Precision Scientific (Chicago, Illinois, USA) Model 6EG Gravity Convection Oven. After drying, the algal cells were pulverized to a fine powder by a mortar and pestle, and kept at $-20^{\circ} \mathrm{C}$ before use.

\section{3 । GC-MS system}

FAME compounds were analyzed by a Varian 3900 GC with a Saturn 2100T ion-trap mass spectrometer using a TRACE TR-FAME GC column $(30 \mathrm{~m} \times 0.25 \mathrm{~mm} \times 0.2 \mu \mathrm{m})$ of Thermo Scientific (Grand Island, NY, USA) with helium as a carrier gas at a constant flow rate of $1.0 \mathrm{~mL} / \mathrm{min}$. For GC separation, sample injector was maintained at $250^{\circ} \mathrm{C}$ and sample injection volume was kept at $1.00 \mu \mathrm{L}$ with a split ratio of $1: 10$. The elution of FAMEs was accomplished within $19.14 \mathrm{~min}$ by a temperature program where the oven temperature was initially set at $40^{\circ} \mathrm{C}$ and kept for $1 \mathrm{~min}$, increased to $180^{\circ} \mathrm{C}$ at $20^{\circ} \mathrm{C} / \mathrm{min}$ and held for $1 \mathrm{~min}$, then increased to $210^{\circ} \mathrm{C}$ at $5^{\circ} \mathrm{C} / \mathrm{min}$ and held for $1 \mathrm{~min}$, and finally increased to $250^{\circ} \mathrm{C}$ at $35^{\circ} \mathrm{C} / \mathrm{min}$ and held for $2 \mathrm{~min}$ before returning to the initial temperature. For MS detection, electron impact (EI) ionization energy was determined by automatic gain control (AGC) ranging 50-150 eV (depending on prescan segment and maximum ionization time). The optimized ionization parameters were as follows: target TIC, 11000 counts; maximum ionization time, $25000 \mu \mathrm{s}$; prescan ionization time, $100 \mu \mathrm{s}$; background mass, $40 \mathrm{~m} / \mathrm{z}$; and RF dump, $650 \mathrm{~m} / \mathrm{z}$. Mass spectra were obtained in the mass range of 50 to 410 amu. Quantitation of FAMEs was carried out by extracted ion chromatogram (EIC) mode with a solvent delay of 3 min for MS data acquisition. The quantifier and qualifier ions used in the GC-MS analyses are listed in Table 1 . The resultant chromatograms and mass spectra were viewed and processed by Varian MS workstation with service pack 6.8 .

\section{4 | Preparation of standard solutions}

The mix standard stock solutions $(10.0 \mathrm{~mm})$ of palmitic acid, palmitoleic acid, stearic acid, oleic acid, linoleic acid and linolenic acid were prepared in methanol. The standard stock solutions $(10.0 \mathrm{~mm})$ of pentadecanoic-2,2- $\mathrm{d}_{2}$ acid (as surrogate analyte for fatty acids in the studies of matrix effect, recovery and stability in algal matrix) and glyceryl tri(hexadecanoate-2,2- $\mathrm{d}_{2}$ ) (as surrogate analyte for glycerolipids in the studies of matrix effect, recovery and stability in algal matrix or as the secondary internal standard (IS) for the analysis of glycerolipids from algal dry mass) were prepared individually in methanol and chloroform. The standard stock solution $(10.0 \mathrm{~mm})$ of tridecanoic-2,2- $\mathrm{d}_{2}$ acid (as the primary IS in all the experiments) was prepared in methanol. All the above stock solutions were kept in glass vials and stored at $-20^{\circ} \mathrm{C}$ before use.

The mix standard working solutions $(1.00$ and $5.00 \mathrm{~mm})$ of palmitic acid, palmitoleic acid, stearic acid, oleic acid, linoleic acid and linolenic acid were prepared by diluting its mix standard stock solution in methanol/chloroform $(4: 1, v / v)$. The standard working solutions $(1.00$ and $5.00 \mathrm{~mm})$ of pentadecanoic-2,2- $\mathrm{d}_{2}$ acid and glyceryl tri(hexadecanoate$2,2-\mathrm{d}_{2}$ ) were prepared separately by diluting their standard stock solutions in methanol/chloroform $(4: 1, \mathrm{v} / \mathrm{v})$. The IS working solutions $(1.00 \mathrm{~mm})$ of tridecanoic-2,2$\mathrm{d}_{2}$ acid and glyceryl tri(hexadecanoate-2,2- $\mathrm{d}_{2}$ ) were prepared separately by diluting their standard stock solutions in methanol/chloroform $(4: 1, \mathrm{v} / \mathrm{v})$.

For the optimization of GC separation conditions, FAME mix standard solution (50.0 ng FAMEs/mL hexane) was prepared by serial dilutions of the AOCS Mix 6 in hexane.

For the optimization of esterification of free fatty acids and transesterification of glycerolipids, and the conversion/yield studies, the solvent mix QCs of palmitic acid, palmitoleic acid, stearic acid, oleic acid, linoleic acid and linolenic acid $(1.50,200,400$ and $500 \mu \mathrm{M})$ were prepared freshly by mixing appropriate amounts of each standard working solutions in known volumes of methanol/chloroform $(4: 1, \mathrm{v} / \mathrm{v})$. The solvent QCs glyceryl tri(hexadecanoate-2,2- $\left.\mathrm{d}_{2}\right)(0.600$, $80.0,160$ and $200 \mu \mathrm{M}$ ) were prepared freshly by serial dilutions of its standard working solution in methanol/chloroform $(4: 1, v / v)$. The standard FAME calibrators $(0.500,1.00,5.00$, $10.0,50.0,100$ and $500 \mu \mathrm{M})$ of methyl myristate (C14:0), 
T A B L E 1 The quantifier and qualifier ions used in GC-MS analyses of FAMEs from algae Scenedesmus dimorphus lipid extract

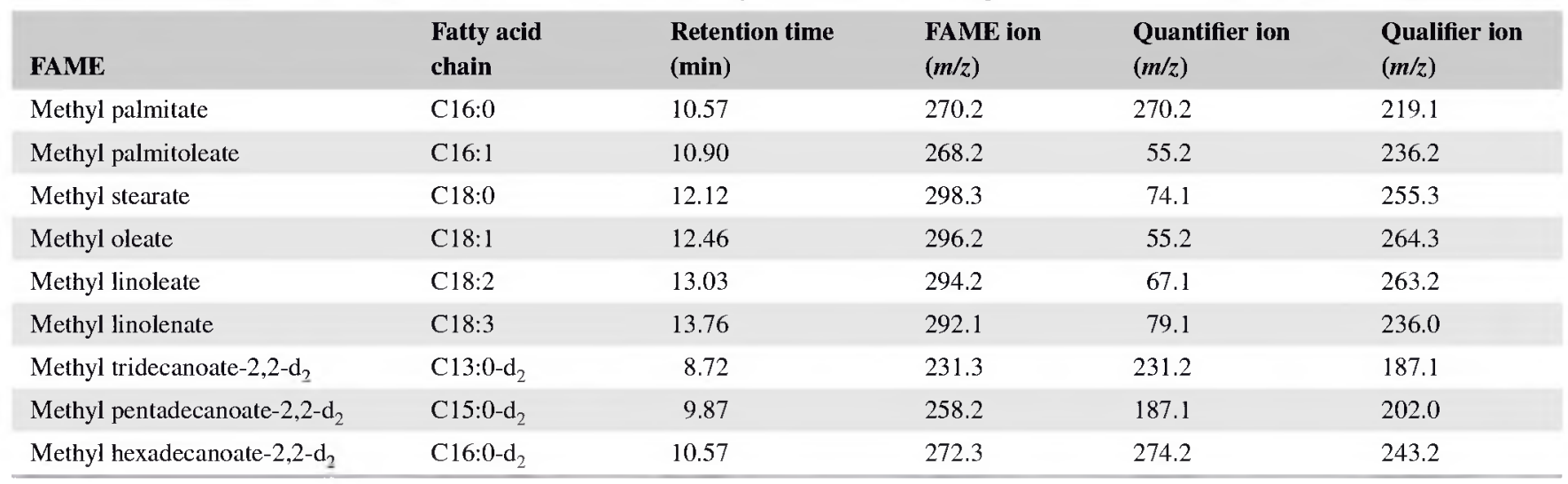

methyl palmitate (C16:0), methyl palmitoleate (C16:1, cis), methyl stearate (C18:0), methyl oleate (C18:1, cis-9), methyl linoleate $(\mathrm{C} 18: 2, c i s, c i s)$ and methyl linolenate $(\mathrm{C} 18: 3$, all cis) were prepared individually by serial dilutions of the AOCS Mix 6 in hexane.

For the studies of LLOQ, intra- and inter-run precision and accuracy, and linear calibration ranges, the solvent mix standard calibrators of palmitic acid, palmitoleic acid, stearic acid, oleic acid, linoleic acid and linolenic acid $(0.500,1.00,5.00$, $10.0,50.0,100$ and $500 \mu \mathrm{M}$ ) and glyceryl tri(hexadecanoate$\left.2,2-\mathrm{d}_{2}\right)(0.200,1.00,5.00,10.0,50.0,100$ and $200 \mu \mathrm{M})$ with a fixed concentration $(50.0 \mu \mathrm{M})$ of IS (tridecanoic-2,2$\mathrm{d}_{2}$ acid), and the solvent mix QCs of palmitic acid, palmitoleic acid, stearic acid, oleic acid, linoleic acid and linolenic acid fatty acids $(0.500,1.50,200$ and $400 \mu \mathrm{M})$ and glyceryl tri(hexadecanoate- $\left.2,2-\mathrm{d}_{2}\right)(0.200,0.600,80.0$ and $160 \mu \mathrm{M})$ with a fixed concentration $(50.0 \mu \mathrm{M})$ of IS (tridecanoic-2,2- $\mathrm{d}_{2}$ acid) were prepared freshly by mixing appropriate amounts of each standard working solutions in known volumes of methanol/chloroform $(4: 1, \mathrm{v} / \mathrm{v})$.

For the studies of matrix effect, recovery and stability in algal matrix, the solvent mix QCs of pentadecanoic-2,2- $\mathrm{d}_{2}$ acid $(1.50,200$ and $400 \mu \mathrm{M})$ and glyceryl tri(hexadecanoate$\left.2,2-\mathrm{d}_{2}\right)(0.600,80.0$ and $160 \mu \mathrm{M})$ containing a fixed concentration $(50.0 \mu \mathrm{M})$ of IS (tridecanoic-2,2- $\mathrm{d}_{2}$ acid) were prepared freshly by diluting each standard working solutions in known volumes of methanol/chloroform $(4: 1, \mathrm{v} / \mathrm{v})$.

For the composition and content analyses of fatty acids and glycerolipids in algae Scenedesmus dimorphus dry mass, the solvent mix calibrators of palmitic acid, palmitoleic acid, stearic acid, oleic acid, linoleic acid and linolenic acid $(0.500,1.00,5.00,10.0,50.0,100$ and $500 \mu \mathrm{M})$ with dual ISs (tridecanoic-2,2- $\mathrm{d}_{2}$ acid, $50.0 \mu \mathrm{M}$; and glyceryl tri(hexadecanoate-2,2- $\left.\mathrm{d}_{2}\right), 20.0 \mu \mathrm{M}$ ), and the solvent mix QCs of palmitic acid, palmitoleic acid, stearic acid, oleic acid, linoleic acid and linolenic acid fatty acids $(1.50,200$ and $400 \mu \mathrm{M}$ ) with dual ISs (tridecanoic-2,2- $\mathrm{d}_{2}$ acid, and $50.0 \mu \mathrm{M}$; glyceryl tri(hexadecanoate-2,2- $\mathrm{d}_{2}$ ), $20.0 \mu \mathrm{M}$ ) were prepared freshly by mixing appropriate amounts of each standard working solutions in known volumes of methanol/chloroform $(4: 1, \mathrm{v} / \mathrm{v})$.

\section{5 | Preparation of QCs in algal matrix before and after extraction and fractionation}

The algal matrix mix QCs of pentadecanoic-2,2- $\mathrm{d}_{2}$ acid $(1.50,200$ and $400 \mu \mathrm{M})$ and glyceryl tri(hexadecanoate-2,2$\left.\mathrm{d}_{2}\right)(0.600,80.0$ and $160 \mu \mathrm{M})$ with a fixed concentration $(50.0 \mu \mathrm{M})$ of IS (tridecanoic-2,2- $\mathrm{d}_{2}$ acid) before the extraction and fractionation of lipids were prepared by transferring $300 \mu \mathrm{L}$ of each corresponding solvent mix QCs into individual borosilicate glass tubes $(12 \times 75 \mathrm{~mm})$ from Fisher Scientific (Hanover Park, IL, USA), then drying under nitrogen before adding $3.00 \mathrm{mg}$ of algal dry mass to each tube, whereas the corresponding algal matrix QCs after the extraction and fractionation of lipids were prepared by spiking $300 \mu \mathrm{L}$ of each corresponding solvent mix QCs into each tube containing the dried residuals of after extraction and fractionation of $3.00 \mathrm{mg}$ algal dry mass (see Sections 2.6 and 2.7).

\section{6 | Algal lipid extraction}

The total lipids in algal dry mass were extracted by the modified Folch method which has high recoveries towards fatty acids, polar and neutral lipids [26]. Since there were different usages of algal dry masses (i.e., one for fatty acids content and composition analyses, and others for preparation of algal matrix mix QCs (see Section 2.5)), the details of extraction procedures were as follows: For content and composition analyses of fatty acids, $3.00 \mathrm{mg}$ of algal dry mass in a borosilicate glass tube $(12 \times 75 \mathrm{~mm})$ was first wetted by $300 \mu \mathrm{L}$ of methanol/chloroform $(2: 1 \mathrm{v} / \mathrm{v})$, then followed by addition of $25.0 \mu \mathrm{L}$ of $1.00 \mathrm{~mm}$ tridecanoic-2,2- $\mathrm{d}_{2}$ acid (the IS for analysis of FAMEs from the fraction of free fatty acids) and $10.0 \mu \mathrm{L}$ of $1.00 \mathrm{~mm}$ glyceryl trihexadecanoate-2,2- $\mathrm{d}_{2}$ (the IS for analysis of FAMEs from the fraction of glycerolipids). For the preparation of algal matrix mix QCs, $3.00 \mathrm{mg}$ of algal dry 

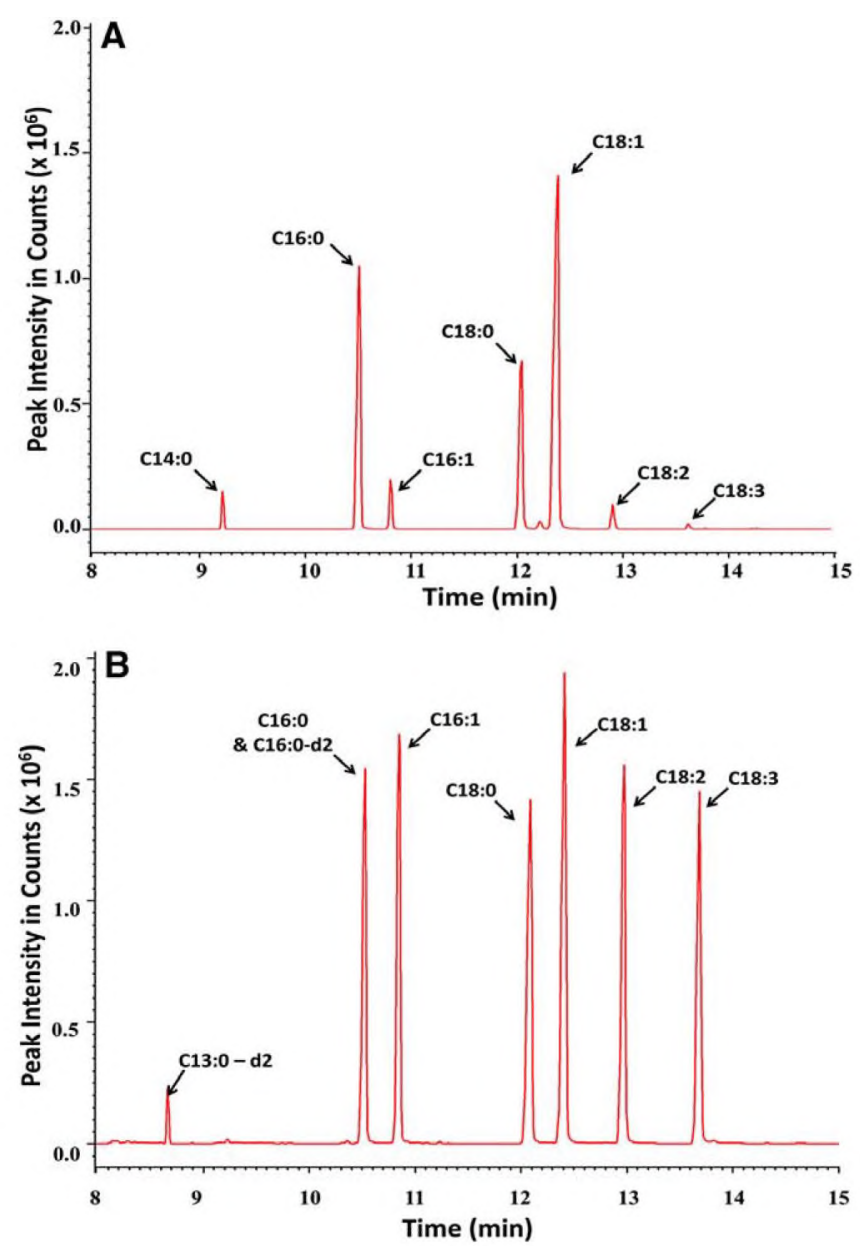

F I G U R E 1 Total ion chromatograms: (A) diluted AOCS mix 6 standard solution $(100 \mu \mathrm{g}$ total FAMEs $/ \mathrm{mL})$; and (B) products of esterification of tridecanoic-2,2- $\mathrm{d}_{2}$ acid, palmitic acid, palmitoleic acid, stearic acid, oleic acid, linoleic acid and linolenic acid, and product of transesterification of glyceryl tri(hexadecanoate- $2,2-\mathrm{d}_{2}$ ), and the concentrations of fatty acids and glycerolipid were $200 \mu \mathrm{M}$ and $5.00 \mu \mathrm{M}$ respectively. The GC-MS conditions were the same as described in Section 2.3

mass in a borosilicate glass tube $(12 \times 75 \mathrm{~mm})$ was first wetted by $300 \mu \mathrm{L}$ of methanol/chloroform $(2: 1 \mathrm{v} / \mathrm{v})$, then followed by addition of $35.0 \mu \mathrm{L}$ of methanol/chloroform $(4: 1, \mathrm{v} / \mathrm{v})$. After acidifying each sample with $15.0 \mu \mathrm{L}$ of $0.1 \mathrm{~N} \mathrm{HCl}$, each tube was vortexed for $5 \mathrm{~min}$ before adding $300 \mu \mathrm{L}$ of chloroform; then, each tube was vortexed for $5 \mathrm{~min}$, and followed by addition of $200 \mu \mathrm{L}$ of deionized water, and vortexing for $2 \mathrm{~min}$. At the end, the solution was centrifuged at $872 \times g$ for $5 \mathrm{~min}$, the lower organic phase was transferred to a clean borosilicate glass tube. The upper aqueous phase was re-extracted with $300 \mu \mathrm{L}$ of chloroform by vortexing and centrifuging for 5 min each. The organic phase of the second extraction was transferred and combined with the organic phase from the first extraction. The combined organic extract (i.e., total algal lipid extract) was used for lipid fractionation.

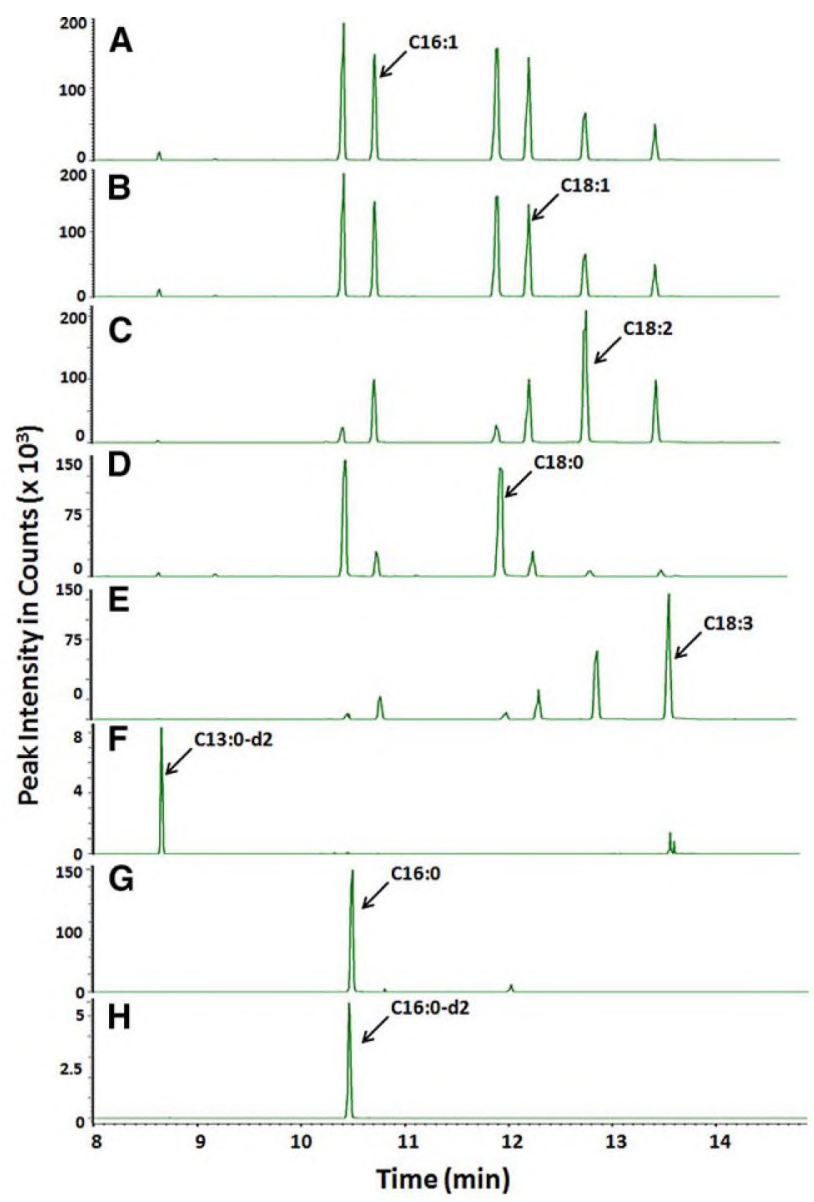

F I G URE 2 Representative extracted ion chromatograms of FAME products from esterification of fatty acids and transesterification of glycerolipid. (A) methyl palmitoleate (C16:1) at $\mathrm{m} / \mathrm{z} 55.2$; (B) methyl oleate (C18:1) at $\mathrm{m} / \mathrm{z} 55.2$; (C) methyl linoleate (C18:2) at $\mathrm{m} / \mathrm{z} 67.1$; (D) methyl stearate (C18:0) at $\mathrm{m} / \mathrm{z} 74.1$; (E) methyl linolenate $(\mathrm{Cl} 18: 3)$ at $\mathrm{m} / \mathrm{z}$ 79.1; (F) methyl tridecanoate-d2 (C13:0-d2) at $\mathrm{m} / \mathrm{z} 231.2$; (G) methyl palmitate $(\mathrm{C} 16: 0)$ at $\mathrm{m} / \mathrm{z} 270.2$; $(\mathrm{H})$ methyl hexadecanoate- $\mathrm{d} 2$ (C16:0d2) at $\mathrm{m} / \mathrm{z}$ 274.2. Experimental conditions were the same as those in Figure $1 b$

\section{7 | Fractionation of free fatty acids and glycerolipids by SPE}

The total algal lipid extract was fractionated into fractions of glycerolipids and free fatty acids by the SPE method developed by Kaluzny et al. [27]. In this method, the total lipid extract was loaded onto a $500 \mathrm{mg}$ aminopropyl cartridge from Agilent technologies (Wilmington, Delaware, USA), which was pre-conditioned with $3 \mathrm{~mL}$ of hexane. Then, $6 \mathrm{~mL}$ of chloroform/isopropanol $(2: 1, \mathrm{v} / \mathrm{v})$ was added to the cartridge to elute the neutral lipid fraction (i.e., cholesterols, cholesteryl esters, triglycerides, diglycerides and monoglycerides). After washing the cartridge with $3 \mathrm{~mL}$ of $2 \%$ acetic acid in diethyl ether, another $6 \mathrm{~mL}$ of $2 \%$ acetic acid in diethyl ether was added to elute the free fatty acids fraction. It was noted that chlorophyll (a major interferent to the analysis of neutral lipids 
and free fatty acids) remained on the cartridge together with polar lipid fraction.

The neutral lipid fraction was then dried in a TurboVap® LV evaporator (Biotage, Charlotte, NC, USA) at room temperature under nitrogen (15 psi) for $50 \mathrm{~min}$, and reconstituted in $1 \mathrm{~mL}$ of hexane. To separate glycerolipids from other neutral lipids, a cascade of two aminopropyl SPE cartridges connected sequentially with Agilent Bond Elut adapter was used, which was pre-conditioned with $3 \mathrm{~mL}$ of hexane. The neutral lipid fraction in hexane was loaded on the first cartridge of the cascade. Then, $3 \mathrm{~mL}$ of $1 \%$ diethyl ether and $10 \%$ dichloromethane in hexane was added and the eluate containing triglyercides was collected at the end of second cartridge. After disposal of the second cartridge from the cascade, which retained cholesteryl ester escaped from the first one, the first cartridge was washed with $4 \mathrm{~mL}$ of $5 \%$ ethyl acetate in hexane to remove cholesterol. Following that, $3 \mathrm{~mL}$ of $15 \%$ ethyl acetate in hexane was added to the cartridge to elute diglycerides. Finally, $3 \mathrm{~mL}$ of chloroform/methanol $(2: 1$, v/v) was added to the cartridge to elute monoglycerides. The tri-, diand monoglycerides were collected into the same borosilicate glass tube, which is known as the glycerolipid fraction. A schematic illustration of the fractionations of free fatty acids and glycerolipids can be found in the reference [27].

For algal fatty acids content and composition analyses (see Section 2.6), the fractions of free fatty acids and glycerolipids were dried individually in the TurboVap ${ }^{\circledR}$ LV evaporator at room temperature under nitrogen (15 psi) for 20 and $50 \mathrm{~min}$, respectively, and each dried residual was reconstituted in $300 \mu \mathrm{L}$ of methanol/chloroform $(4: 1, \mathrm{v} / \mathrm{v})$. For algal matrix mix QCs spiked in before extraction, both fatty acids and glycerolipid fractions were mixed and dried, and the dried residual was reconstituted in $300 \mu \mathrm{L}$ of methanol/chloroform $(4: 1, \mathrm{v} / \mathrm{v})$ (see Section 2.5). For algal matrix mix QCs spiked in after extraction, both fatty acids and glycerolipid fractions were mixed and dried, and the dried residual was spiked in $300 \mu \mathrm{L}$ of solvent mix QCs in methanol/chloroform $(4: 1, \mathrm{v} / \mathrm{v})$ (see Section 2.5).

\subsection{Optimized conditions for esterification of fatty acids}

$300 \mu \mathrm{L}$ of the solvent mix QCs of fatty acids (see Section 2.4) (or the reconstituted free-fatty-acid fraction from the total algal lipid extract (Section 2.7)) were mixed with $500 \mu \mathrm{L}$ of $\mathrm{BCl}_{3}$-methanol $(12 \% \mathrm{w} / \mathrm{w})$ and $15.0 \mu \mathrm{L}$ of $2,2-$ dimethoxypropane in a $3 \mathrm{~mL}$ clear micro-reaction vessel (Type I) from Sigma-Aldrich (St. Louis, MO, USA). After tightening the vial cap to prevent evaporation of solvent and entry of moisture from the atmosphere, the esterification reaction was allowed to proceed at $100^{\circ} \mathrm{C}$ for $15 \mathrm{~min}$ in the convection oven by placing the micro-reaction vessel inside a sand bath containing sea sand from Fisher
Scientific (Hanover Park, IL, USA). After cooling the microreaction vessel to room temperature, $500 \mu \mathrm{L}$ of deionized water and $300 \mu \mathrm{l}$ of hexane were added. The extraction of the reaction products (FAMEs) by hexane was achieved by vortexing the liquids inside the micro-reaction vessel for $5 \mathrm{~min}$. Then, $100 \mu \mathrm{L}$ of the upper hexane layer containing FAMEs were transferred into a $150 \mu \mathrm{L}$ glass inserted in an autosampler vial from Fisher Scientific (Hanover Park, IL, USA) which was capped afterward for GC-MS analysis.

\subsection{Optimized conditions for transesterification of glycerolipids}

$300 \mu \mathrm{L}$ of the solvent QCs glyceryl tri(hexadecanoate2,2- $\mathrm{d}_{2}$ ) (Section 2.4) (or reconstituted glycerolipid fraction from the total algal lipid extract (Section 2.7)) was mixed with $500 \mu \mathrm{L}$ of $\mathrm{BCl}_{3}$-methanol $(12 \% \mathrm{w} / \mathrm{w})$ and $15.0 \mu \mathrm{L}$ of 2,2-dimethoxypropane in a $3 \mathrm{~mL}$ clear micro-reaction vessel. After tightening the vial cap, the transesterification reaction was allowed to proceed at $100^{\circ} \mathrm{C}$ for $50 \mathrm{~min}$ in the convection oven by placing the micro-reaction vessel inside a sand bath. After cooling the micro-reaction vessel to room temperature, $500 \mu \mathrm{L}$ of deionized water and $300 \mu \mathrm{L}$ of hexane were added. The extraction of the reaction products (FAMEs) by hexane was achieved by vortexing the liquids inside the microreaction vessel for $5 \mathrm{~min}$. Then, $100 \mu \mathrm{L}$ of the upper hexane layer containing FAMEs were transferred into a $150 \mu \mathrm{L}$ glass inserted in an autosampler vial which was capped afterward for $\mathrm{GC}-\mathrm{MS}$ analysis.

\subsection{0 | Method validation}

The GC-MS method developed was validated in reference to the US-FDA guidance for industry (2001) on bioanalytical method validation [28] in terms of matrix effect, recovery, LLOQ, linear calibration range, accuracy and precision, as well as stability.

\subsection{1 $\mid$ Recovery and matrix factor}

The absolute recovery of fatty acid or glycerolipid was determined by the mean peak area of fatty acid or glycerolipid at a specific concentration in algal matrix over the mean peak area of fatty acid or glycerolipid at the concentration in the extracted/fractionated algal matrix multiplying by $100 \%$, and the IS normalized recovery was determined by the absolute recovery of fatty acid or glycerolipid over that of the IS multiplying by $100 \%$; whereas the absolute matrix factor (MF) of fatty acid or glycerolipid was determined by the mean peak area of fatty acid or glycerolipid at a specified concentration in the extracted/fractionated algal matrix over that of fatty acid or glycerolipid at the concentration in the solvent, and the IS normalized MF was determined by the absolute MF of fatty acid or glycerolipid over that of the IS. 
In this study, algal matrix mix QCs of pentadecanoic-2,2- $\mathrm{d}_{2}$ acid $(1.50,200$ and $400 \mu \mathrm{M})$ and glyceryl tri(hexadecanoate$\left.2,2-\mathrm{d}_{2}\right)(0.600,80.0$ and $160 \mu \mathrm{M})$ with a fixed concentration $(50.0 \mu \mathrm{M})$ of IS (tridecanoic-2,2- $\mathrm{d}_{2}$ acid) before the extraction and fractionation (Section 2.5) were subjected to sample extraction and fractionation (Sections 2.6 and 2.7). The reconstituted solutions ( $300 \mu \mathrm{L}$ each) together with equal volume of the corresponding algal matrix mix QC after the extraction and fractionation and equal volume of the corresponding solvent mix QC were undergone esterification/transesterification reactions (Sections 2.8 and 2.9), and the resulting FAME compounds were measured by GC-MS. Three parallel measurements of three identical QC samples at each QC concentration were performed, and the data were used to calculate the mean recoveries and MFs.

\subsection{2 $\mid$ LLOQ}

The LLOQ of the method for an analyte was defined as the concentration of standard calibrator at the lowest concentration of the analyte in a calibration plot, which had accuracy and precision of $\leq \pm 20 \%$ and $20 \%$ by five replicate measurements in the solvent matrix.

\subsubsection{Calibration curves}

For the composition and content analyses of FAME compounds generated by the free-fatty-acid fraction and glycerolipid fraction of algae dry mass, calibration curves of FAME compounds were prepared by the reactions of $\mathrm{BCl}_{3}$ $\mathrm{MeOH}$ with the solvent mix calibrators of palmitic acid, palmitoleic acid, stearic acid, oleic acid, linoleic acid and linolenic acid, together with dual ISs (i.e., tridecanoic-2,2$\mathrm{d}_{2}$ acid for free fatty acids, and glyceryl tri(hexadecanoate$2,2-d_{2}$ ) for glycerolipids). Each calibration curve consisted of a double blank (with neither analytes nor ISs), a single blank (without analytes but ISs: tridecanoic-2,2- $\mathrm{d}_{2}$ acid, $50.0 \mu \mathrm{M}$; and glyceryl tri(hexadecanoate-2,2- $\left.\mathrm{d}_{2}\right), 20.0 \mu \mathrm{M}$ ), and seven non-zero standard calibrators $(0.500,1.00,5.00$, $10.0,50.0,100$ and $500 \mu \mathrm{M}$ with the ISs). The calibration curve of a FAME compound from the fraction of free fatty acids was constructed using the peak area ratios of an analyte to tridecanoic-2,2- $\mathrm{d}_{2}$ acid $(y)$ versus the analyte concentrations $(x)$ with $1 / x$ weighting, whereas the calibration curve of a FAME compound from the fraction of glycerolipids was constructed using the peak area ratios of an analyte to glyceryl tri(hexadecanoate-2,2- $\left.\mathrm{d}_{2}\right)(y)$ versus the analyte concentrations $(x)$ with $1 / x$ weighting.

\subsubsection{Accuracy and precision}

Accuracy was expressed as percentage relative error (RE) and precision as the coefficient of variation (CV). In this work, the inter-assay accuracy and precision were assessed by five parallel analyses of five identical solvent QC samples at each of the three QC concentrations (for mix fatty acids: 1.50, 200 and $400 \mu \mathrm{M}$, and for lipid (glyceryl tri(hexadecanoate-2,2- $\left.\mathrm{d}_{2}\right)$ ): $0.600,80.0$ and $160 \mu \mathrm{M})$ over five separate days. The intraassay accuracy and precision were assessed by five replicate analyses of each QC samples in the same day.

\subsection{5 | Stability}

The stabilities of fatty acids and glycerolipids were investigated using standard stock solutions of pentadecanoic2,2- $\mathrm{d}_{2}$ acid $(10.0 \mathrm{~mm})$ and glyceryl tri(hexadecanoate-2,2$\left.\mathrm{d}_{2}\right)(10.0 \mathrm{~mm})$, low- and high-QCs in algal matrix of pentadecanoic-2,2- $\mathrm{d}_{2}$ acid $(1.50$ and $400 \mu \mathrm{M})$ and glyceryl tri(hexadecanoate-2,2- $\left.\mathrm{d}_{2}\right)(0.600$ and $160 \mu \mathrm{M})$ with tridecanoic-2,2- $\mathrm{d}_{2}$ acid $(50.0 \mu \mathrm{M})$ as the internal standard.

The stabilities of the stock standards and QCs were assessed for short-term storage ( 6 and $24 \mathrm{~h} ; 23^{\circ} \mathrm{C}$ ) on bench top (pre-preparative) and in autosampler (post-preparative); three freeze-thaw cycles (where the samples were subjected to freezing temperature at $-20^{\circ} \mathrm{C}$ for at least $24 \mathrm{~h}$ and thawed at $23^{\circ} \mathrm{C}$ (room temperature) unassisted. The stabilities expressed as percent recoveries were determined by comparing the mean-peak-area ratios of the analyte to the IS in the test samples to those of freshly prepared samples. For this study, all measurements were done in five replicates.

\subsection{1 | Method application}

The validated GC-MS method was applied to the composition and content analyses of fatty acids from the fractions of free fatty acids and glycerolipids in algae Scenedesmus dimorphus dry mass. Algal cells were grown and prepared by the procedures described in Section 2.2. During the analysis, algal samples together with nine solvent mix standard calibrators (i.e., double- and single-blank, and seven non-zero), and a set of solvent mix QCs (at low, medium and high concentrations) were processed by the procedures described in Sections 2.6 2.9 and analyzed by the method described in Section 2.3.

\section{3 | RESULTS AND DISCUSSION}

\section{1 | Method development}

\subsection{1 | GC-MS}

A Thermo Scientific ${ }^{\mathrm{TM}}$ TRACE $^{\mathrm{TM}}$ TR-FAME capillary GC column was used for this study because of its high-polarity cyanopropylphenyl-based phase for separation of FAMEs and cis/trans isomers with various degrees of unsaturation. The TR-FAME column provided not only higher separation efficiency of FAMEs, but also provided better resolution, reproducibility and more symmetrical peaks. GC separation of FAMEs was initially tested on this column using FAME mixed standard solution prepared from the AOCS Mix 6 . The 


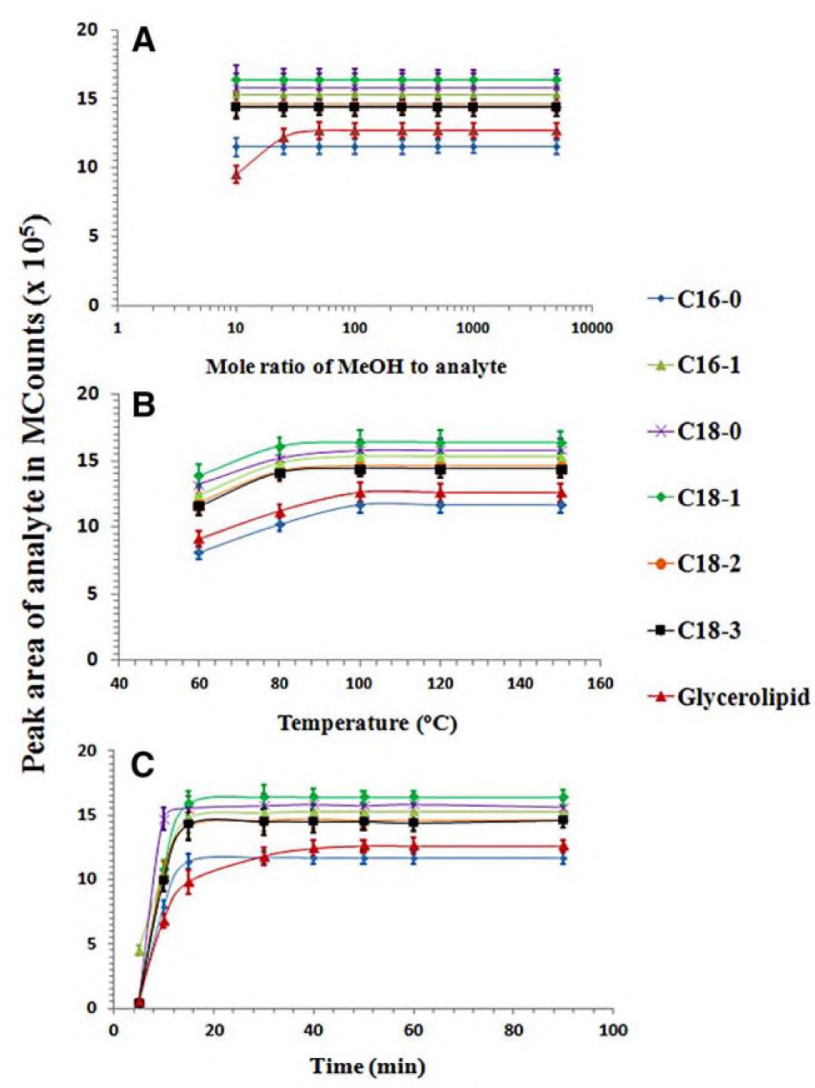

F I G U RE 3 Optimization of reaction conditions of one-step esterification/transesterification of fatty acids and glycerolipid. Experimental conditions were as follows: (A) fatty acids, $500 \mu \mathrm{M}$; glyceryl tri(hexadecanoate-2,2- $\mathrm{d}_{2}$ ), $200 \mu \mathrm{M}$; $\mathrm{MeOH}$ with $12 \% \mathrm{BCl}_{3}$ w/w; reaction temperature, $100^{\circ} \mathrm{C}$; reaction time, $15 \mathrm{~min}$ for fatty acids and $50 \mathrm{~min}$ for glyceryl tri(hexadecanoate-2,2- $\mathrm{d}_{2}$ ); (B) same as (A) except the mole ratio of $\mathrm{MeOH}$ to analyte was at $162: 1$; and (C) same as (B) except the reaction temperature was at $100^{\circ} \mathrm{C}$

temperature program (Section 2.3) was chosen because its ramping rate at $5^{\circ} \mathrm{C} / \mathrm{min}$ was particularly effective to resolve the isomeric analytes of methyl stearate and methyl linolenate between $180^{\circ} \mathrm{C}$ and $210^{\circ} \mathrm{C}$. For this work, the injector temperature was maintained at $250^{\circ} \mathrm{C}$ to ensure complete vaporization of analytes and $1.00 \mu \mathrm{L}$ injection with a split ratio of $1: 10$ was chosen to minimize sample zone broadening. The FAMEs of interest for this work were resolved in less than 14 min with a total program run time of 19.14 min (Fig. 1a). These optimized GC conditions were later applied to the separation of the products of fatty acid esterification and glycerolipid transesterification (Fig. 1b).

Quantitation of the FAMEs were carried out by the extracted ion chromatogram (EIC) mode of the ion-trap mass spectrometer with the quantifier and qualifier ions listed in Table 1. Although some FAME compounds shared the same quantifier ions (i.e., $m / z 55.2$ for methyl palmitoleate and methyl oleate), these compounds could be resolved by GC and identified by their unique qualifier ions; whereas the coeluted FAME compounds (i.e., methyl hexadecanoate-2,2- $\mathrm{d}_{2}$ and methyl palmitate) could be quantified by their unique quantifier and qualifier ions. The representative EIC mass chromatograms for various FAME compounds are given in Fig. 2, which demonstrated the unparalleled selectivity of the GCMS method.

\subsection{2 | Use of stable heavy isotopes as surrogate analytes and internal standards}

Due to the endogenous nature of fatty acids and glycerolipids in algae, stable heavy isotopes pentadecanoic-2,2- $\mathrm{d}_{2}$ acid and glyceryl tri(hexadecanoate-2,2- $\mathrm{d}_{2}$ ) were employed as surrogate analytes for the assessment of matrix effect, recovery, and stability of fatty acids and glycerolipids in algal matrix. Since the matrix effect was negligible (Section 3.2.1), the method developed was then using solvent mix standard calibrators of fatty acids and glycerolipid validated in terms of lower limits of quantitation, linear calibration ranges, intra- and interassay precision and accuracy. In these experiments, a single stable heavy isotope (tridecanoic-2,2- $\mathrm{d}_{2}$ acid) was used as the IS because neither fatty acids nor glycerolipids was fractionated. However, when the method developed was applied to the quantitation of FAME compounds from free fatty acid and glycerolipid fractions of algae Scenedesmus dimorphus dry mass, dual stable isotopes (tridecanoic-2,2- $\mathrm{d}_{2}$ acid for free fatty acids, and glyceryl tri(hexadecanoate-2,2- $\mathrm{d}_{2}$ ) for glycerolipids) were used for both calibration plots and algal sample preparation because fractionations of fatty acids and glycerolipids were performed.

\subsection{3 | One-step esterification of free fatty acids and transesterification of glycerolipids}

Fatty acids and glycerolipids are not very volatile by nature; therefore, when measuring them by $\mathrm{GC}-\mathrm{MS}$, it is common to convert these compounds into the more volatile FAMEs. In this work, $\mathrm{BCl}_{3}-\mathrm{MeOH}(12 \% \mathrm{w} / \mathrm{w})$ was used as the esterifying reagent for one-step esterification of fatty acids or transesterification of glycerolipids. Compared to $\mathrm{BF}_{3}-\mathrm{MeOH}$, another frequently used esterifying reagent, $\mathrm{BCl}_{3}-\mathrm{MeOH}$ was found not only to be more stable when stored properly and to produce less artifacts $[29,30]$, but also is suited for both esterification of fatty acids and transesterification of glycerolipids without prior hydrolysis [31,32].

The strategy on the use of $\mathrm{BCl}_{3}-\mathrm{MeOH}$ as an esterifying reagent for one-step esterification of fatty acids and transesterification of lipids was developed in the 1960s [31] and modified in the 1970s [32] using chemical standards. This strategy and its reaction conditions derived from chemical standards in the early works were adopted to various sample analyses, such as musk melon leaves [33], vegetable oils [34] and corn grains [35] without further optimization.

In our work, we not only applied the strategy of using $\mathrm{BCl}_{3}$ $\mathrm{MeOH}$ for one-step transesterification of lipids for the first 
TA B L E 2 Matrix effect and recovery of fatty acid and glycerolipid from algal matrix

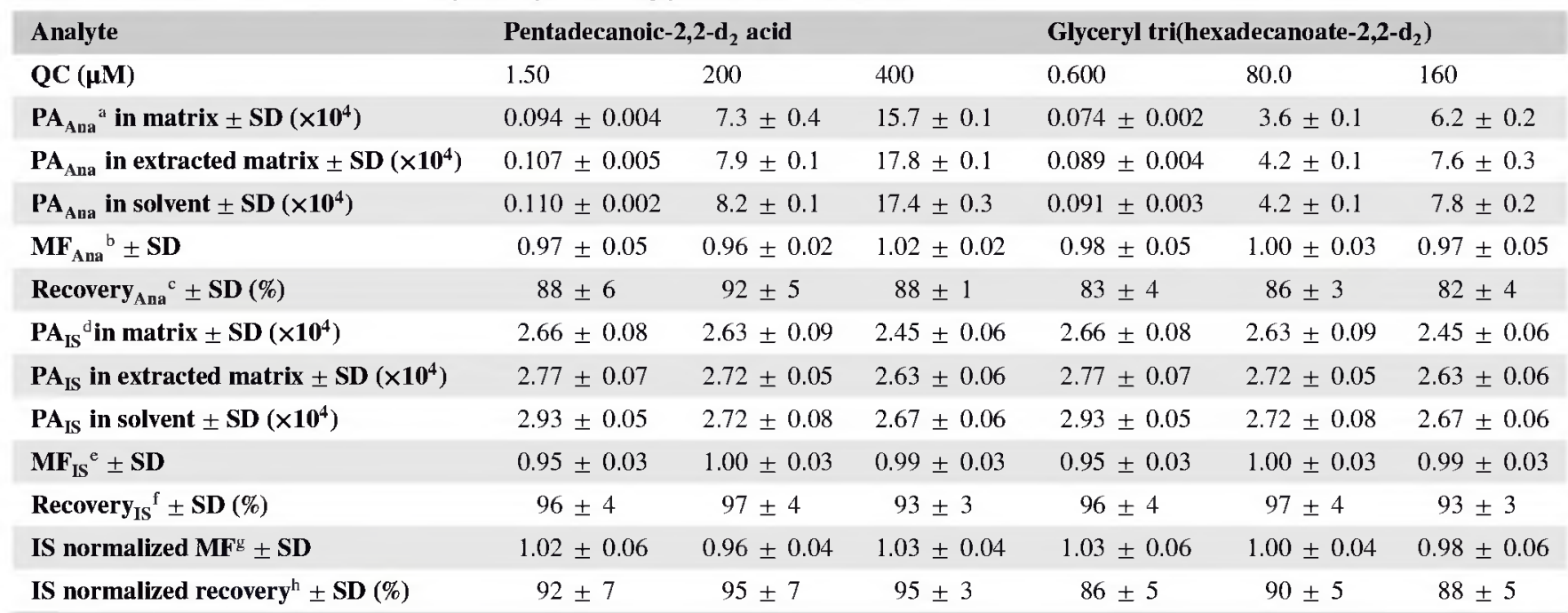

${ }^{\mathrm{a}} \mathrm{PA}_{\mathrm{Ana}}=$ mean peak area of analyte.

${ }^{\mathrm{b}} \mathrm{MF}_{\mathrm{Ana}}=\left(\mathrm{PA}_{\mathrm{Ana}}\right.$ in extracted algal matrix $) /\left(\mathrm{PA}_{\mathrm{Ana}}\right.$ in solvent $)$

${ }^{\mathrm{c}} \mathrm{Recovery}_{\mathrm{Ana}}=\left[\left(\mathrm{PA}_{\mathrm{Ana}}\right.\right.$ in algal matrix $) /\left(\mathrm{PA}_{\mathrm{Ana}}\right.$ in extracted algal matrix $\left.)\right] \times 100 \%$.

${ }^{\mathrm{d}} \mathrm{PA}$ IS $=$ mean peak area of internal standard.

${ }^{\mathrm{e}} \mathrm{MF}_{\mathrm{IS}}=\left(\mathrm{PA}_{\mathrm{IS}}\right.$ in extracted algal matrix $) /\left(\mathrm{PA}_{\mathrm{IS}}\right.$ in solvent $)$.

${ }^{f_{\text {Recovery }}}{ }_{I S}=\left[\left(\mathrm{PA}_{\mathrm{IS}}\right.\right.$ in algal matrix $) /\left(\mathrm{PA}_{\mathrm{IS}}\right.$ in extracted algal matrix $\left.)\right] \times 100 \%$.

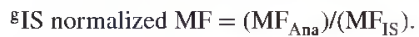

${ }^{\mathrm{h}}$ IS normalized recovery $=\left[\left(\right.\right.$ Recovery $\left._{\text {Ana }}\right) /\left(\right.$ Recovery $\left.\left._{\mathrm{IS}}\right)\right] \times 100 \%$.

Note: The concentration of the IS (tridecanoic-2,2- $\mathrm{d}_{2}$ acid) is $50.0 \mu \mathrm{M}$. All the samples were taken in three replicates.

time in algal samples, but also optimized the reaction conditions in the real sample matrix, which were not done in the previous studies. In detail, to maximize the product yields and improve the reproducibility of the reaction between fatty acids or glycerolipids and $\mathrm{BCl}_{3}-\mathrm{MeOH}$, factors (such as the mole ratio of $\mathrm{MeOH}$ to analyte, reaction temperature, and reaction time) that affect esterification of fatty acids and transesterification of glycerolipids were investigated using analyte concentrations at the upper limits of calibration curves $(500 \mu \mathrm{M}$ for fatty acids and $200 \mu \mathrm{M}$ for glycerolipid).

As shown in Fig. 3, a steady-state production of FAME compounds could be reached at mole ratios of $\mathrm{MeOH}$ to analyte $\geq 10$ for fatty acids and $\geq 25$ for glycerolipid (Fig. 3a) with reaction temperatures $\geq 100^{\circ} \mathrm{C}$ for both fatty acids and glycerolipid (Fig. 3b) and reaction times $\geq 15 \mathrm{~min}$ for fatty acids and $\geq 50$ min for glycerolipid (Fig. 3c). Therefore, for the subsequent studies, the optimum reaction conditions chosen were as follows: a mole ratio of $\mathrm{MeOH}$ to analyte at 162 times over the ones needed to reach the steady-state production of FAMEs, a reaction temperature of $100^{\circ} \mathrm{C}$, and a reaction time of $15 \mathrm{~min}$ for esterification of fatty acids or $50 \mathrm{~min}$ for transesterification of glycerolipids. These optimized conditions showed reductions in both reaction temperature (from 120 to $100^{\circ} \mathrm{C}$ ) and reaction time (from 90 to $50 \mathrm{~min}$ ) in comparison to the previous reports [31-35].

Under the optimum reaction conditions, the conversion rates of fatty acids (i.e., palmitic acid, palmitoleic acid, stearic acid, oleic acid, linoleic acid and linolenic acid at three different concentrations of $1.50,200$ and $400 \mu \mathrm{M}$ ), and glycerolipid (i.e., glyceryl tri(hexadecanoate-2,2- $\mathrm{d}_{2}$ ) acid at three different concentrations of $0.600,80.0$ and $160 \mu \mathrm{M}$ ) to their corresponding FAME compounds were examined, and the conversion yields were calculated using individual calibration curve prepared by individual FAME standard solutions. As summarized in Table S1 (Supporting Information), the conversion yields ranged from 97 to $100 \%$ for fatty acids and 92 to $94 \%$ for glycerolipid.

In our work, we observed that the esterification and transesterification reaction involving $\mathrm{BCl}_{3}-\mathrm{MeOH}$ was sensitive to trace levels of water. Water tends to hinder the reaction producing lower yields of FAMEs. Hence, 2,2-dimethoxy propane was used as a water scavenger and its amount was optimized for the reaction conditions in the real sample matrix. From our experiments, we observed that the levels of 2,2-dimethoxy propane above $15 \mu \mathrm{L}$ were producing spurious peaks between 3 and $5 \mathrm{~min}$ on the chromatogram. Therefore, $15 \mu \mathrm{L}$ was chosen as an optimum amount for the reaction.

\section{2 | Method validation}

\subsection{1 । Recovery and matrix effect}

The recovery and MF data were summarized in Table 2 . As shown in the table, the absolute and the IS normalized recoveries were $88-92$ and $92-95 \%$ for pentadecanoic-2,2- $\mathrm{d}_{2}$-acid, 
T A B L E 3 Intra- and inter-run precision and accuracy of the fatty acids and glycerolipid

\begin{tabular}{|c|c|c|c|c|c|c|c|c|c|c|}
\hline \multicolumn{3}{|l|}{ Analyte } & \multicolumn{4}{|l|}{ Intra-run $(n=5)$} & \multicolumn{4}{|l|}{ Inter-run $(n=5)$} \\
\hline name & Fatty acid chain & [Nominal] ( $\boldsymbol{\mu M}$ ) & [Measured] ( $\boldsymbol{\mu M})$ & $S D(\mu \mathrm{M})$ & $C V(\%)$ & $R E(\%)$ & [Measured] $(\boldsymbol{\mu M})$ & $S D(\mu \mathrm{M})$ & $C V(\%)$ & $R E(\%)$ \\
\hline \multirow[t]{4}{*}{ Palmitic acid } & $\mathrm{C} 16: 0$ & 0.500 (LLOQ) & 0.52 & 0.05 & 9 & 4 & $\mathrm{NM}^{\mathrm{a}}$ & $\mathrm{NM}$ & $\mathrm{NM}$ & NM \\
\hline & & 1.50 & 1.57 & 0.09 & 6 & 4 & 1.42 & 0.1 & 7 & -6 \\
\hline & & 200 & 210 & 9 & 4 & 5 & 190 & 9 & 5 & -5 \\
\hline & & 400 & 382 & 19 & 5 & -5 & 379 & 18 & 5 & -6 \\
\hline \multirow[t]{4}{*}{ Palmitoleic acid } & $\mathrm{C} 16: 1$ & 0.500 (LLOQ) & 0.49 & 0.03 & 6 & -2 & NM & NM & $\mathrm{NM}$ & NM \\
\hline & & 1.50 & 1.43 & 0.08 & 6 & -5 & 1.58 & 0.1 & 7 & 5 \\
\hline & & 200 & 211 & 10 & 5 & 5 & 190 & 12 & 6 & -5 \\
\hline & & 400 & 414 & 22 & 5 & 3 & 420 & 22 & 5 & 5 \\
\hline \multirow[t]{4}{*}{ Stearic acid } & $\mathrm{C} 18: 0$ & 0.500 (LLOQ) & 0.51 & 0.05 & 9 & 3 & NM & NM & NM & NM \\
\hline & & 1.50 & 1.53 & 0.05 & 3 & 2 & 1.43 & 0.1 & 8 & -5 \\
\hline & & 200 & 193 & 8 & 4 & -4 & 209 & 9 & 4 & 4 \\
\hline & & 400 & 383 & 18 & 5 & -4 & 384 & 16 & 4 & -4 \\
\hline \multirow[t]{4}{*}{ Oleic acid } & C18:1 & 0.500 (LLOQ) & 0.48 & 0.03 & 5 & -4 & NM & NM & NM & NM \\
\hline & & 1.50 & 1.44 & 0.08 & 6 & -4 & 1.58 & 0.1 & 7 & 5 \\
\hline & & 200 & 211 & 8 & 4 & 5 & 189 & 8 & 4 & -6 \\
\hline & & 400 & 387 & 23 & 6 & -3 & 378 & 24 & 6 & -6 \\
\hline \multirow[t]{4}{*}{ Linoleic acid } & $\mathrm{C} 18: 2$ & 0.500 (LLOQ) & 0.46 & 0.03 & 6 & -7 & $\mathrm{NM}$ & NM & $\mathrm{NM}$ & NM \\
\hline & & 1.50 & 1.45 & 0.04 & 3 & -3 & 1.49 & 0.1 & 9 & -1 \\
\hline & & 200 & 210 & 9 & 4 & 5 & 195 & 8 & 4 & -3 \\
\hline & & 400 & 423 & 27 & 6 & 5 & 418 & 22 & 5 & 4 \\
\hline \multirow[t]{4}{*}{ Linolenic acid } & $\mathrm{C} 18: 3$ & 0.500 (LLOQ) & 0.47 & 0.03 & 7 & -7 & $\mathrm{NM}$ & NM & $\mathrm{NM}$ & NM \\
\hline & & 1.50 & 1.47 & 0.06 & 4 & -2 & 1.42 & 0.09 & 6 & -6 \\
\hline & & 200 & 192 & 9 & 5 & -4 & 189 & 8 & 4 & -6 \\
\hline & & 400 & 381 & 21 & 6 & -5 & 415 & 26 & 6 & 4 \\
\hline \multirow[t]{4}{*}{ Glyceryl tri(hexa decanoate-2,2- $\mathrm{d}_{2}$ ) } & $\mathrm{C} 16: 0-\mathrm{d}_{2}$ & 0.200 (LLOQ) & 0.18 & 0.01 & 9 & -9 & NM & NM & NM & NM \\
\hline & & 0.600 & 0.58 & 0.04 & 7 & -3 & 0.57 & 0.04 & 7 & -5 \\
\hline & & 80.0 & 84 & 6 & 7 & 5 & 83 & 7 & 7 & 4 \\
\hline & & 160 & 168 & 13 & 8 & 5 & 168 & 19 & 9 & 5 \\
\hline
\end{tabular}

${ }^{\mathrm{a}} \mathrm{NM}=$ not measured

Note: The concentration of the IS (tridecanoic-2,2- $\mathrm{d}_{2}$ acid) is $50.0 \mu \mathrm{M}$. All the samples were taken in five replicates. 
T A B L E 4 Stability studies of fatty acid and glyerolipid in stock solutions and algal matrix

\begin{tabular}{|c|c|c|c|c|c|c|c|c|c|}
\hline \multirow{3}{*}{ Test conditions } & \multirow{3}{*}{ Temp. $\left({ }^{\circ} \mathrm{C}\right)$} & \multicolumn{4}{|c|}{ Pentadecanoic-2,2- $d_{2}$ acid } & \multicolumn{4}{|c|}{ Glyceryl tri(hexadecanoate-2,2-d ${ }_{2}$ ) } \\
\hline & & \multirow[t]{2}{*}{ [Analyte] $(\boldsymbol{\mu M})$} & \multicolumn{2}{|c|}{ Recovery $\pm S D(\%)$} & & \multirow[t]{2}{*}{ [Analyte] $(\mu \mathrm{M})$} & \multicolumn{3}{|c|}{ Recovery $\pm S D(\%)$} \\
\hline & & & $6 \mathrm{~h}$ & $24 \mathrm{~h}$ & & & $6 \mathrm{~h}$ & $24 \mathrm{~h}$ & \\
\hline \multirow{2}{*}{ Bench-top } & & 400 (stock) & $96 \pm 3$ & $93 \pm 2$ & & 160 & $94 \pm 4$ & $90 \pm 3$ & \\
\hline & & $1.50(\mathrm{LQC})$ & $98 \pm 3$ & $87 \pm 4$ & & 0.600 & $94 \pm 4$ & $86 \pm 3$ & \\
\hline \multirow[t]{2}{*}{ Autosampler } & 23 & $1.50(\mathrm{LQC})$ & $91 \pm 4$ & $89 \pm 2$ & & 0.600 & $93 \pm 3$ & $89 \pm 3$ & \\
\hline & & $400(\mathrm{HQC})$ & $93 \pm 4$ & $89 \pm 3$ & & 160 & $92 \pm 3$ & $89 \pm 2$ & \\
\hline \multirow{2}{*}{$\begin{array}{l}3 \text { Freeze-thaw } \\
\text { cycles }\end{array}$} & -20 to 23 & $1.50(\mathrm{LQC})$ & & & $90 \pm 4$ & 0.600 & & & $88 \pm 4$ \\
\hline & & $400(\mathrm{HQC})$ & & & $90 \pm 4$ & 160 & & & $90 \pm 4$ \\
\hline
\end{tabular}

Note: The concentration of the IS (tridecanoic-2,2- $\mathrm{d}_{2}$ acid) is $50.0 \mu \mathrm{M}$. All the samples were taken in five replicates.

and $82-86$ and $86-90 \%$ for glyceryl tri(hexadecanoate2,2- $\left.\mathrm{d}_{2}\right)$; and the absolute and the IS normalized MFs were $0.96-1.02$ and $0.96-1.03$ for pentadecanoic-2,2- $\mathrm{d}_{2}$-acid, and $0.97-1.00$ and $0.98-1.03$ for glyceryl tri(hexadecanoate$2,2-\mathrm{d}_{2}$ ), respectively.

In comparison to the previous analytical methods for algal sample analyses $[18,24]$, which did not carry out method validation in algal matrix and simply applied solvent calibrators for quantitation of FAME compounds, our studies addressed the concern of matrix effect and revealed that matrix effect on analytical signals were insignificant and negligible, and the recoveries of the FAME compounds from algal matrix were high enough for accurate quantitation with the use of internal standard. Therefore, solvent calibrators instead of matrix calibrators were used in the subsequent quantitative studies.

\subsubsection{Calibration curves and lower limits of quantitation}

The linear calibration curves of methyl esters of palmitic acid, palmitoleic acid, stearic acid, oleic acid, linoleic acid and linolenic acid were established from 0.500 to $500 \mu \mathrm{M}$, and the calibration equations were provided in Table S2 (Supporting Information). The LLOQs of these FAME compounds derived from free fatty acids and glycerolipid were 0.500 and $0.200 \mu \mathrm{M}$, respectively, which had accuracy and precision of $\leq \pm 7 \%$ and $\leq 9 \%$ for free fatty acids, and $\leq \pm 9 \%$ and $\leq 9 \%$ for glycerolipid, by five replicate measurements in solvent matrix (Table 3).

\subsection{3 | Accuracy and precision}

As shown in Table 3 , the intra-assay accuracy and precision were $\leq \pm 5 \%$ and $\leq 6 \%$ for the fatty acids and $\leq \pm 5 \%$ and $\leq 8 \%$ for the glycerolipid, and the inter-assay accuracy and precision were $\leq \pm 6 \%$ and $\leq 9 \%$ for the fatty acids and $\leq \pm 5 \%$ and $\leq 9 \%$ for the glycerolipid, indicating the method developed was both accurate and precise.

\subsection{4 | Stability}

The stability studies of the standard stock solutions of pentadecanoic-2,2- $\mathrm{d}_{2}$ acid $(10.0 \mathrm{~mm})$ and glyceryl tri(hexadecanoate-2,2- $\left.\mathrm{d}_{2}\right)(10.0 \mathrm{~mm})$, and low- and highQCs of pentadecanoic-2,2- $\mathrm{d}_{2}$ acid $(1.50$ and $400 \mu \mathrm{M})$ and glyceryl tri(hexadecanoate-2,2- $\left.\mathrm{d}_{2}\right)(0.600$ and $160 \mu \mathrm{M})$ in algal matrix were conducted. As summarized in Table 4, at room temperature $\left(23^{\circ} \mathrm{C}\right)$, the stock solutions and the algal matrix QCs were stable for up to $24 \mathrm{~h}$ on bench top (pre-preparative) and in autosampler (post-preparative) at room temperature $\left(23^{\circ} \mathrm{C}\right)$ with recoveries ranged $86-99 \%$ for pentadecanoic-2,2- $\mathrm{d}_{2}$ acid, and $84-95 \%$ for glyceryl tri(hexadecanoate-2,2- $\mathrm{d}_{2}$ ). For three freeze-thaw cycles, the recoveries were $90 \%$ for pentadecanoic-2,2- $d_{2}$ acid, and $88-90 \%$ for glyceryl tri(hexadecanoate- $2,2-d_{2}$ ). The data indicated that there were no significant losses of analytes during sample analyses.

\section{3 | Analysis of fatty acids in algae Scenedesmus dimorphus}

The validated GC-MS method was applied to the determination of saturated and unsaturated fatty acids with carbon numbers of 16 and 18 (i.e., palmitic acid (C16:0), palmitoleic acid (C16:1), stearic acid (C18:0), oleic acid (C18:1), linoleic acid (C18:2) and linolenic acid (C18:3)) in the fractions of free fatty acids and glycerolipids from total lipid extract of algae Scenedesmus dimorphus dry mass. By the procedures described in Section 2.11, the free fatty acids and glycerolipids were converted into FAMEs and detected by the GC-MS method developed (Fig. 4). The quantitation of individual fatty acid was accomplished by individual FAME calibration curves whose data were obtained concurrently with those of algal samples. As shown in Table 5, the sum of six fatty acids from the free fatty acid fraction of the total lipid extract was $4.44 \%$ of the algal dry mass, 

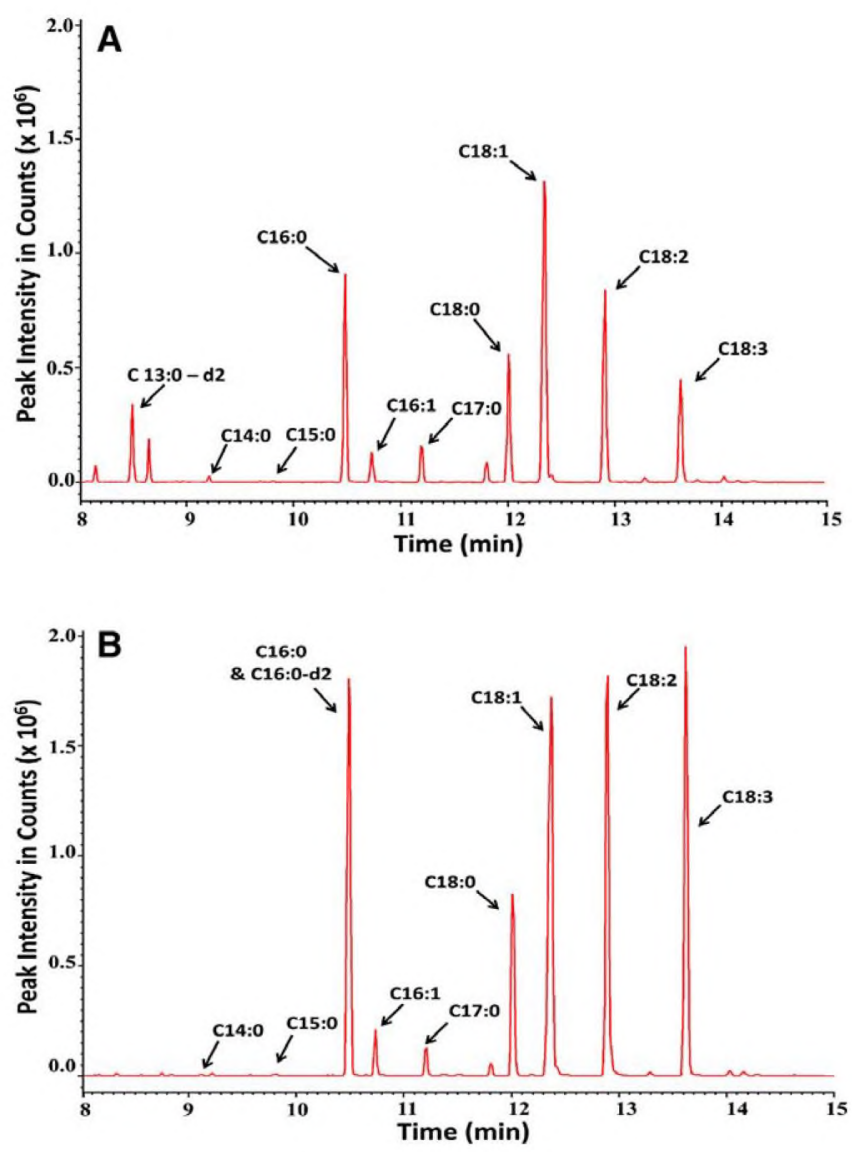

F I G U RE 4 Total ion chromatograms of FAMEs from algae Scenedesmus dimorphus dry mass. (A) The fraction of free fatty acids from total algal lipid extract (tridecanoic-2,2- $\mathrm{d}_{2}$ acid was used as the IS at the concentration of $50.0 \mu \mathrm{M}$ ); and (B) the fraction of glycerolipids from total algal lipid extract [glyceryl tri(hexadecanoate-2,2- $\mathrm{d}_{2}$ ) was used as the IS at the concentration of $20.0 \mu \mathrm{M}$ ]. Experimental conditions were the same as those described in the Section 2.11

whereas the sum of six fatty acids from the glycerolipid fraction was $6.83 \%$. These data are in concordance with the previous findings $[18,24]$. The compositions of fatty acids found in the fraction of free fatty acids from the total algal lipid extract match those reported in the Superpathway of Fatty Acid Biosynthesis II of the green algae family Scenedesmaceae [36], whereas the fatty acids found in the fraction of glycerolipids from the total algal lipid extract match those reported in the Biosynthesis Pathway of Diacylglycerol and Triacylglycerol [37].

\section{4 | CONCLUSION}

This paper detailed the development and validation of a quantitative analytical method for the determination of fatty acids in both free fatty acid and glycerolipid fractions of total lipid extract from algae Scenedesmus dimorphus dry mass. In this work, the total lipids were first extracted by a modified Folch method, then free fatty acids and glycerolipids were fractionated by aminopropyl SPE cartridges. This method employed a time-efficient one-step esterification and transesterification reaction to convert free fatty acids and glycerolipids to FAME compounds, which were optimized in terms of reactant ratio, reaction temperature and time. The separation and quantitation of FAME compounds were accomplished by GC-MS. The method developed has been validated in terms of matrix effect, recovery, LLOQ, linear calibration range, accuracy and precision, as well as stabilities. It has been successfully applied to the analysis of fatty acids in algae Scenedesmus dimorphus, and can be used for quality assessment of biodiesel produced from algal biomass.

\section{ACKNOWLEDGMENTS}

S.G.C.A. would like to thank Tyler Kutchta, Chris Hardulak and Grace Mahofouz in the Department of Chemical and Biomedical Engineering at Cleveland State University for providing the algal samples used in this study. This work was supported by the funding provided by the Cleveland State University, Office of Research Internal Funding program, Dissertation Research Award.

T A B LE 5 The content of fatty acids as FAMEs from the fractions of free fatty acids and glycerolipids of algal lipid extract

\begin{tabular}{|lll|}
$\begin{array}{l}\text { Fraction of algal } \\
\text { lipid extract }\end{array}$ & Fatty acid chain & $\begin{array}{l}\text { Content of fatty } \\
\text { acid in algal dry } \\
\text { mass (\%) }\end{array}$ \\
\hline Free fatty acids ${ }^{\mathrm{a}}$ & $\mathrm{C} 16: 0$ & 0.685 \\
& $\mathrm{C} 16: 1$ & 0.327 \\
& $\mathrm{C} 18: 0$ & 0.174 \\
& $\mathrm{C} 18: 1$ & 0.804 \\
& $\mathrm{C} 18: 2$ & 1.19 \\
\hline Sum of free fatty & $\mathrm{C} 18: 3$ & 1.26 \\
acids & & 4.44 \\
\hline Glycerolipids ${ }^{\mathrm{b}}$ & $\mathrm{C} 16: 0$ & 1.04 \\
& $\mathrm{C} 16: 1$ & 0.531 \\
& $\mathrm{C} 18: 0$ & 0.240 \\
& $\mathrm{C} 18: 1$ & 1.58 \\
\hline Sum of fatty acids & $\mathrm{C} 18: 2$ & 1.63 \\
\hline from glycerolipids & $\mathrm{C} 18: 3$ & 1.81 \\
\hline
\end{tabular}

${ }^{\mathrm{a}}$ Tridecanoic-2,2- $\mathrm{d}_{2}$ acid was used as the IS at a concentration of $50.0 \mu \mathrm{M}$.

${ }^{\mathrm{b}}$ Glyceryl tri(hexadecanoate-2,2- $\mathrm{d}_{2}$ ) was used as the IS at a concentration of $20.0 \mu \mathrm{M}$.

Note: All the samples were taken in three replicates. 


\section{REFERENCES}

1. Gupta, V. K., Tuohy, M., Kubicek, C. P., Saddler, J., Feng, X. Bioenergy Research: Advances and Applications, 1st Edition, Elsevier, London, 2014.

2. European biofuels technology platform, Micro- and macroalgae: utility for industrial applications 2007. Available from http://www.biofuelstp.eu/downloads/epobio_aquatic_report.pdf (accessed 2016 Nov 27).

3. Demirbas, A., Demirbas, M. F., Importance of algae oil as a source of biodiesel. Energ. Convers. Manage. 2011, 52, 163-170.

4. Chisti, Y., Biodiesel from microalgae. Biotechnol Adv. 2007, 25, 294-306.

5. Gressel, J., Transgenics are imperative for biofuel crops. Plant Sci. 2008, 174, 246-262.

6. Ho, S.-H., Chen, C.-Y., Chang, J.-S., Effect of light intensity and nitrogen starvation on $\mathrm{CO}_{2}$ fixation and lipid/carbohydrate production of an indigenous microalga Scenedesmus obliquus CNW-N. Bioresource Technol. 2012, 113, 244-252.

7. Liu, J., Yuan, C., Hu, G., Li, F., Effects of light intensity on the growth and lipid accumulation of microalga Scenedesmus sp. 111 under nitrogen limitation. Appl. Biochem. Biotechnol. 2012, 166. 2127-2137.

8. Converti, A., Casazza, A. A., Ortiz, E. Y., Perego, P., Borghi, M. D., Effect of temperature and nitrogen concentration on the growth and lipid content of Nannochloropsis oculata and Chlorella vulgaris for biodiesel production. Chem. Eng. Process. 2009, 48. 11461151.

9. Aslan, S., Kapdan, I. K., Batch kinetics of nitrogen and phosphorus removal from synthetic wastewater by algae. Ecol. Eng. 2006, 28, 64-70.

10. Goldberg, I. K., Cohen, Z., The effect of phosphate starvation on the lipid and fatty acid composition of the fresh water eustigmatophyte Monodus subterraneus, Phytochemistry. 2006, 67, 696-701.

11. Han, X., Miao, X. L., Wu, Q. Y., High quality biodiesel production from a microalga Chlorella protothecoides by heterotrophic growth in fermenters. J. Biotechnol. 2006, 126, 499-507.

12. Abd El Baky, H., El Baz, F. K., El-Baroty, G. S., Over-production of lipid rich in $\gamma$-lininolenic acid by blue green alga Spirulina maxima and its inhibitory effect on carcinoma cells. Adv. Food Sci. 2006, 4, 206-212.

13. Liquid transportation fuels from coal and biomass: technological statis, costs, and environmental impact, National Academy of Sciences, National Academy of Engineering, and National Research Council, The National Academies, Washington, DC 2009.

14. MacDougall, K. M., McNichol, J., McGinn, P. J., O’Leary, S. J. B., Melanson, J. E., Triacylglycerol profiling of microalgae strains for biofuel feedstock by liquid chromatography-highresolution mass spectrometry. Anal. Bioanal. Chem. 2011, 401, 2609-2616.

15. Knothe, G., Dependence of biodiesel fuel properties on the structure of fatty acid alkyl esters, Fuel Process Technol. 2005, 86. 10591070.
16. Lee, S. J., Go, S., Jeong, G. T., Kim, S. K., Oil production from five marine microalgae for the production of biodiesel. Biotechnol. Bioprocess. Eng. 2011, 16, 561-566.

17. Knothe, G., Improving biodiesel fuel properties by modifying fatty ester composition. Energ. Environ. Sci. 2009, 2, 759-766.

18. Renaud, S. M., Parry, D. L., Thinh, L. V., Microalgae for use in tropical aquaculture I: gross chemical and fatty acid composition of twelve species of microalgae from the Northern Territory, Australia. J. Appl. Phycol. 1994, 6, 337-345.

19. Chen, W., Sommerfeld, M., Hu, Q., Microwave-assisted nile red method for in vivo quantification of neutral lipids in microalgae. Bioresour. Technol. 2011, 102, 135-141.

20. Soh, L., Zimmerman, J., Biodiesel production: the potential of algal lipids extracted with supercritical carbon dioxide. Green Chem. 2011, 13, 1422-1429.

21. MeNichol, J., MacDougall, K. M., Melanson, J. E., McGinn, P. J,, Suitability of Soxhlet extraction to quantify microalgal fatty acids as determined by comparison with in situ transesterification. Lipids 2012, 47, 195-207.

22. Sakthivel, R., Elumalai, S., Santhiya, S. J., Fatty acids methyl ester analysis of potent micro algae Scenedesmus dimorphus (Turpin) Kützing and Chlorococcum infusionum (Schrank) Meneghini isolated from effluents of Neyveli thermal power station expansion 1. J. Algal. Biomass Utln. 2012, 3, 12-20.

23. Shah, G. C., Patidar, A., Urkude, V., Hurmale, A., Choudhary, S., Yadav, M., Tiwari, A., Analysis and characterization of algal oil by different chromatographic techniques for the high production of biodiesel from scenedesmus dimorphus. Int. J. Environ. Bioenerg. 2012, 4, 22-35.

24. Paik, M.-J., Kim, H., Lee, J., Brand, J., Kim, K.-R., Separation of triacylglycerols and free fatty acids in microalgal lipids by solidphase extraction for separate fatty acid profiling analysis by gas chromatography. J. Chromatogr. A. 2009, 1216, 5917-5923.

25. Welter, C., Schwenk, J., Kanani, B., Blargan, J. V., Belovich, J. M., Minimal medium for optimal growth and lipid production of the microalgae Scenedesmus dimorphus. Environ. Prog. Sustain. Energy 2013, 32, 937-945.

26. Folch, J., Lees, M., Sloane Stanley, G. H., A simple method for the isolation and purification of total lipids from animal tissues. J. Biol. Chem. 1957, 226, 497-509.

27. Kaluzny, M. A., Duncan, L. A., Merritt, M. V., Epps, D. E., Rapid separation of lipid classes in high yield and purity using bonded phase columns. J. Lipid. Res. 1985, 26, 135-140.

28. US-FDA, Guidance for industry: bioanalytical method validation, 2001. Available from http://www.fda.gov/downloads/Drugs/ GuidanceComplianceRegulatoryInformation/Guidances/UCM070 107.pdf (accessed 2016 Nov 27).

29. Lough, A. K., The production of methoxy-substituted fatty acids as artifacts during the esterification of unsaturated fatty acids with methanol containing boron trifluoride, J. Biochem. 1964, 90, 4C$5 \mathrm{C}$.

30. Orgambide, G. G., Reusch, R. N., Dazzo, F. B., Methoxylated fatty acids reported in Rhizobium isolates arise from chemical alterations of common fatty acids upon acid-catalyzed transesterification procedures. J. Bacterol. 1993, 175, 4922-4926. 
31. Morrison, W. R., Smith, L. M., Preparation of fatty acid methyl esters and dimethylacetals from lipids with boron fluoridemethanol, J. Lipid Res. 1964, 5, 600-608.

32. Klopfenstein, W. E., On methylation of unsaturated acids using boron trihalide- methanol reagents. J. Lipid. Res. 1971, 12, 773776.

33. Lester, G., Plasma membrane from muskmelon leaves: purification and lipid composition during growth at 15 or $30^{\circ} \mathrm{C}$. J. Amer. Soc. Hort. Sci. 1990, 115, 274-277.

34. Stavarache, C., Vinatoru, M., Maeda, Y., Ultrasonic versus silent methylation of vegetable oils. Ultrason. Sonochem. 2006, 13, 401407.

35. Depenbusch, B. E., Coleman, C. M., Higgins, J. J., Drouillard, J. S., Effects of increasing levels of dried corn distillers grains with solubles on growth performance, carcass characteristics, and meat quality of yearling heifers. J. Anim. Sci. 2009, 87, 2653-2663.

36. MetaCyc pathway: superpathway of fatty acid biosynthesis II (plant). Available from http://biocyc.org/META/NEW-IMAGE? type=PATHWAY\&object=PWY-5156\&detail-level=2 (accessed 2016 Nov.27).
37. MetaCyc pathway: diacylglycerol and triacylglycerol biosynthesis. Available from: http://metacyc.org/META/NEW-IMAGE?type= NIL\&object=TRIGLSYN-PWY\&redirect $=$ T $($ accessed 2016 Nov 27).

\section{SUPPORTING INFORMATION}

Additional Supporting Information may be found online in the supporting information tab for this article.

How to cite this article: Avula SGC, Belovich JM, Xu Y. Determination of fatty acid methyl esters derived from algae Scenedesmus dimorphus biomass by GC-MS with one-step esterification of free fatty acids and transesterification of glycerolipids. $J$ Sep Sci. 2017;40:2214-2227. https://doi.org/10.1002/ jssc. 201601336 